\title{
НЕКОТОРЫЕ ОСОБЕННОСТИ ОРГАНИЗАЦИИ САМООБРАЗОВАТЕЛЬНОЙ ДЕЯТЕЛЬНОСТИ ОБУЧАЮЩИХСЯ В МАГИСТРАТУРЕ
}

\author{
A. А. Фортунатов \\ Московский гуманитарный университет
}

Аннотация: В данной статье раскрываются основные направления организации самообразовательной деятельности студентов магистратуры, обучающихся по направлению подготовки - 44.04.02 «Психолого-педагогическое образование».

Ключевые слова: самообразование; самообразовательная деятельность; магистратура; психолого-педагогическое образование

\section{SOME FEATURES OF THE ORGANIZATION OF SELF-EDUCATIONAL ACTIVITY OF GRADUATE STUDENTS}

\author{
A. A. Fortunatov \\ Moscow University for the Humanities
}

Аннотация: This article reveals the main directions of the organization of selfeducational activities of graduate students specializing in 44.04.02 «Psychological and pedagogical education».

Ключевые слова: self-education; self-educational activity; graduate school; psychological and pedagogical education

На сегодняшний день обществом востребована личность, обладающая не только необходимыми знаниями, умениями и навыками (ЗУН) или точнее всего знанием, пониманием и умением (ЗПУ), но и самостоятельностью, организованностью, способностью решать творческие задачи, проектировать собственную деятельность, готовностью к самообразованию и саморазвитию, к ускоренной адаптации к изменениям в социокультурном пространстве. В нашей работе мы основываемся на мнении И. М. Ильинского, который говорит о недостаточности формулы ЗУНов и о важности формулы ЗПУ. Автор отмечает, что конечным смыслом образования является не знание, а именно понимание. Кризис понимания, пишет И. М. Ильинский, основывается на избытке информации в образовании и науке, а дальнейшее наращивание только компонента знаний бессмысленно (Ильинский, 2014: 10). 
В целом организация самообразовательной деятельности помогает студенту найти индивидуальные смыслы, которые он постигает своим неповторимым путем.

Прежде чем рассматривать проблему организации самообразовательной деятельности обучающихся в магистратуре, остановимся на понятии «самообразование» и раскроем основные его составляющие.

Сам термин «самообразование» достаточно часто интересует исследователей и поэтому регулярно встречается в научной литературе. Несмотря на это, прийти к какому-то общему определению у исследователей до сих пор так и не получилось. Причина этого кроется в многогранности исследуемого явления. В изучении проблемы самообразования активно принимают ученые-педагоги.

В процессе изучения психолого-педагогической литературе нам удалось насчитать более сотни определений понятия «самообразования». Анализируя данные дефиниции, нам удалось вычленить основные составные компоненты «самообразования», которые характеризуют его в большей степени:

- самообразование представляет собой социальный процесс, на прямую связанный с реализацией деятельности человека с целью его профессионального самосовершенствования (Вишневская, Вишневская, 2009; Третьяков, 2007; Климова, Юревич, 2013; Фролова, 2011);

- самообразование можно рассмотреть как целенаправленно организованную, самодеятельную, систематическую познавательную деятельность (Павлова, 2011);

- самообразование рассматривается как деятельность, основанная на самопознании и осуществляемая на уровне самовоспитания (Яковлева, 2010; Бузарова, 2005; Старикова, 2014; Байлук, 2011);

- самообразование является высшей формой выражения личности, в процессе которого задействованы как физические, так и духовные силы личности и основанное на тесной взаимосвязи педагога и обучающегося (Зборовский, Шуклина, 2003);

- самообразование раскрывается как деятельность, которая выстраивается на основе рефлексивных процессов, ведущая к формированию самостоятельности в деятельности обучающихся (Юденко, 2007; Галустов, 2011; Камьянов, 2011; Баньковская, 2011);

- самообразование представляет собой разновидность мотивационно-смысловой сферы человека, в результате чего происходит его саморазвитие и самоизменение, основанные на изменении самосознания личности (Кирилаш, Лукашова, 2007);

- самообразование представляет собой разновидность специфической системы познавательных умений, сформированных в результате педагоги- 
ческой поддержке (Минина, 2013; Беткер, 2010).

Исходя из проведенного выше обозначенного анализа работ, нами были подтверждены объективные выводы, касающиеся особенностям самообразования обучающихся, основанного на специфике субъекта и условиях в которых оно осуществляется, изложенные в работе «Формирование экологического самообразования студентов вуза с помощью активных методов обучения» (Фортунатов, 2008).

Рассмотрим особенности организации самообразовательной деятельности обучающихся в магистратуре в АНО ВО «Московский государственный университет» на примере программы «Научно-исследовательская работа» (НИР) по направлению подготовки - 44.04.02 «Психолого-педагогическое образование», профиль подготовки - «Педагогика и психология высшей школы», квалификация выпускника - магистр, которая ведется нами (Фортунатов, 2018).

Целью программы «Научно-исследовательская работа» является - развитие у магистранта методологической компетентности, необходимой для самостоятельного осуществления научно-исследовательской работы, непосредственно связанной с реализацией сложных профессиональных действий в условиях современного образования;

Основными задачами программы являются:

- обеспечение условий для выявления магистрантами сущности методологического знания;

- формирование комплекса ценностно-эмоциональных отношений начинающих исследователей к методологической компетентности как необходимой предпосылке успешной научно-исследовательской деятельности в высшей школе;

- использование актуальных образовательных технологий, основывающихся на сборе и обработке информации, ее интерпретации в психолого-педагогическом исследовании;

- анализ и обобщение результатов, основанных на различных социальных проектах в психолого-педагогической области;

- экспертиза образовательных программ, проектов, психолого-педагогических технологий с точки зрения их соответствия возрастным возможностям обучающихся и соответствия современным научным психологическим подходам в возрастной, педагогической и социальной психологии;

- использование методик, основанных на психолого-педагогической диагностики;

- повышение психологической компетентности обучающихся, разработка и реализация программ имеющих психолого-педагогическую направленность. 
Процесс реализации программы «Научно-исследовательская работа» направлен на формирование следующих компетенций (Федеральный государственный образовательный стандарт...., 2016: Электр. ресурс):

-ПК-36 - готовность использовать современные научные методы для решения научных исследовательских проблем;

- ПК-37 - способность разработать и представить обоснованный перспективный план научной исследовательской деятельности;

-ПК-39 - способность выстроить менеджмент социализации результатов научных исследований;

-ПК-40 - способность представлять научному сообществу научные исследовательские достижения в виде научных статей, докладов, мультимедийных презентаций в соответствии с принятыми стандартами и форматами профессионального сообщества;

- ПК-41 - способность выделять научную исследовательскую проблему в контексте реальной профессиональной деятельности и проектировать программы ее изучения.

Содержание НИР обучающихся в магистратуре создавалось с учетом интересов и возможностей выпускающей кафедры педагогики и психологии высшей школы. Программа НИР для каждого магистранта конкретизируется и дополняется в зависимости от специфики и характера выполняемой работы. Предусмотрены следующие этапы реализации программы:

1. Подготовительный этап

Составляется план работы; осуществляется ознакомление с информационно-методическими источниками; теоретическая подготовка по программе научно-исследовательской работы.

2. Основной этап

Сбор, анализ и интерпретация, полученной информации; оказание помощи в организации и проведении научно-практических конференций, круглых столах, дискуссиях, диспутах, организуемых выпускающей кафедрой; участие в конкурсах научно-исследовательских работ.

3. Заключительный этап

Подготовка отчѐта по научно-исследовательской работе; прохождение процедуры защиты отчета.

В процессе реализации данной программы обучающимся необходимо выполнить следующие задания, направленные на организацию их самообразовательной деятельности:

1. Задание № 1. На основе изучения научных трудов и интересов всех преподавателей кафедры, необходимо сформулировать и обосновать единую тему научной работы кафедры.

При этом необходимо учитывать: 
- понимание всеми членами кафедры актуальности предлагаемой темы;

- учет инновационных научных особенностей каждого члена кафедры;

- возможность внедрения полученных результатов в учебный процесс; обоснование востребованности полученных результатов в научном сообществе (потенциальная возможность повышения цитируемости авторов-исполнителей).

2. Задание № 2. На основе предоставленного контингента необходимо привлечь не менее 5 обучающихся для их участия в работе научного кружка, который должен учитывать:

- сопряженность темы научного кружка с будущей профессиональной деятельностью;

- реальную возможность использования полученных обучающими научных результатов в публикациях статей, в выступлениях на конференциях, в участии в конкурсах на лучшую студенческую работу и др.;

- возможность привлечения к работе кружка обучающихся других вузов; умение обучающихся выполнять научные исследования как индивидуально, так и в коллективе.

3. В процессе практики обучающиеся принимают участие научно-исследовательской и организационной работе выпускающей кафедры.

4. Конкретное содержание научно-исследовательской работы планируется научным руководителем магистранта и отражается в его отчете по ней.

3. Задание № 3. На основе изучения научных трудов и интересов научного руководителя, необходимо написать статью по содержанию, близкой к теме ВКР. В качестве примера оформления статьи берем электронный журнал «Научные труды МосГУ» выпускаемый издательством АНО ВО «Московский гуманитарный университет».

Проведенный нами теоретический анализ, на наш взгляд, является значимым для осуществления самообразовательной деятельности магистрантов. Знание взаимосвязи способов саморегулирования и мотивации достижения позволяет преподавателю простроить учебный процесс таким образом, чтобы он не вызывал напряжения у обучающегося, которое провоцирует при саморегуляции поведения использовать неконструктивные методы и позволило бы организовать работу по формированию наиболее адекватных способов организации самообразовательной деятельности обучающихся в магистратуре. В дальнейшем нами планируется реализовывать исследование проблемы самообразование у магистрантов. 


\section{СПИСОК ЛИТЕРАТУРЫ}

Байлук, В. В. (2011) Сущность самореализации личности и ее структура // Педагогическое образование в России. № 4. С. 12-17.

Баньковская, Н. И. (2011) Представление о мотивации к самообразованию учащихся в современной психологии // Известия Тульского государственного университета. Гуманитарные науки. № 8. С. 342-352.

Беткер, Л. Ю. (2010) Проблема самообразования педагога // Вестник Югорского государственного университета. № 3 (18). С. 43-46.

Бузарова, Е. А. (2005) Психология личностного и профессионального развития, самовоспитание и самообразования // Вестник Адыгейского государственного университета. № 6. С. 137-143.

Вишневская, Л. П., Вишневская Г. В. (2009) Самообразование как психолого-педагогическая проблема // Известия Пензенского государственного педагогического университета им. В. Г. Белинского. № 12. С. 156-158.

Галустов, А. Р. (2011) Основы проектирования модели готовности студентов к самообразованию // Вестник Адыгейского государственного университета. № 1. С. 46-60.

Зворовский, Г., Шуклина, Е. (2003) Самообразование парадигма XXI века // Высшее образование России. № 5. С. 25-32.

Ильинский, И. М. (2014) «Знание - понимание - умение» как формула перспективной научной и образовательной деятельности // Знание. Понимание. Умение. № 1. С. 5-17.

Камьянов, А. А. (2011) Самообразование студентов в современном вузе (концептуально-технологический аспект) // Интеграция образования. № 2 . C. 25-29.

Кирилаш, А. В., Лукашова, И. А. (2007) Развитие личнсости в процессе самообразования // Педагогика, психология и медико-биологические проблемы физического воспитания и спорта. № 12. С. 16-19.

Климова, Т. Е., Юревич, С. Н. (2013) Самообразование в системе повышения квалификации // Научное обеспечение системы повышения квалификации кадров. № 1 (14). С. 10-16.

Минина, Е. В. (2013) Самообразование как форма самостоятельной работы студентов // Педагогическое образование в России. № 2. С. 54-57.

Павлова, В. А. (2011) Формирование навыков самоорганизации и самообразования студентов технических вузов // Человек и образование. № 4 (29). С. 115-118.

Старикова, Е. П. (2014) Самообразование в структуре социальной стратификации Красноярского края // Интернет-журнал «Науковедение». № 3. С. 51-56. 
Третьяков, Д. В. (2007) Информационные технологии как инструмент развития самообразовательной деятельности студентов // Известия Российского государственного университета им. А. И. Герцена. Т. 6. № 24. С. 365-368.

Федеральный государственный образовательный стандарт высшего образования по направлению подготовки 44.04.02 Психолого-педагогическое образование (уровень магистратуры) (утв. приказом Министерства образования и науки РФ от 12 мая 2016 г. N 549) (2016) [Электронная версия] // Федеральный государственный образовательный стандарт. URL: http://fgosvo. ru/uploadfiles/fgosvom/440402.pdf (дата обращения: 06.07.2018).

Фролова, С. Л. (2011) Мотивация профессионального самообразования студентов // Педагогическое образоване России. № 1. С. 229-233.

Фортунатов, А. А. (2018) Рабочая программа дисциплины «Научно-исследовательская работа» Б2.Н.1. Направление подготовки - 44.04.02 «Психолого-педагогическое образование». Программа - «Педагогика и психология высшей школы». Квалификация (степень) выпускника - магистр. Форма обучения - очная, заочная. М. : МосГУ. 44 с.

Фортунатов А. А. (2008) Формирование экологического самообразования студентов вуза с помощью активных методов обучения: метод. рекомендации для преподавателей вузов. Магнитогорск : Магнитогорский государственный университет. 28 с.

Юденко, Т. А. (2007) Проблема самообразования школьников в отечественной педагогической теории // Наука. Инновации. Технологии. № 47. С. $123-129$.

Яковлева, Г. В. (2010) Управление самообразованием педагогов инновационных дошкольных образовательных учреждений // Известие Самарского научного центра Российской академии наук. № 3. С. 81-89.

Дата поступления: 15.08.2018 2.

Фортунатов Артем Александрович - кандидат педагогических наук, доцент кафедры педагогики и психологии высшей школы Московского гуманитарного университета. Адрес: 111395, Россия, г. Москва, ул. Юности, д. 5 Тел.: +7 (499) 374-74-59. Эл. адрес: art_fortunatov@mail.ru

Fortunatov Artem Alexandrovitch, Candidate of Pedagogy, senior lecturer, Department of the Pedagogy and Psychology of Higher School, Moscow University for the Humanities. Postal address: 5, Yunosti St., Moscow, Russian Federation, 111395. Tel.: +7 (499) 374-74-59. E-mail: art_fortunatov@mail.ru 


\section{Для цитирования:}

Фортунатов А. А. Некоторые особенности организации самообразовательной деятельности обучающихся в магистратуре [Электронный ресурс] // Научные труды Московского гуманитарного университета. 2018. № 4. URL: http://journals.mosgu.ru/trudy/article/view/811 (дата обращения: дд.мм.гг.). DOI: 10.17805/trudy.2018.4.7 